\title{
Residual smear layer after root canal instrumentation by using Niti, M-Wire and CM- Wire instruments: A scanning electron microscopy analysis
}

\author{
Ricardo Machado ${ }^{1}$, Daniel Comparin², Eduardo Donato Eing Engelke Back ${ }^{3}$, \\ Lucas da Fonseca Roberti Garcia ${ }^{4}$, Luiz Rômulo Alberton ${ }^{5}$
}

Correspondence: Dr. Ricardo Machado

Email: ricardo.machado.endo@gmail.com
${ }^{1}$ Clinical Practice Limited to Endodontics, Navegantes, Santa Catarina, Brazil,

${ }^{2}$ Clinical Practice Limited to Endodontics, Cunha Porã, Santa Catarina, Brazil,

${ }^{3}$ Private Clinical Practice, Joinville, Santa Catarina, Brazil,

${ }^{4}$ Department of Dentistry, Division of Endodontics, Health Sciences Center, Federal University of Santa Catarina, Florianópolis, Santa Catarina, Brazil, ${ }^{5}$ Department of Veterinary Medicine, Graduate Program in Animal Science, Paranaense University - UNIPAR, Umuarama, Paraná, Brazil

\section{ABSTRACT}

Objective: The purpose of this study was to compare the amount of residual smear layer after root canal instrumentation by using Ni-Ti, M-Wire, and CM-Wire instruments. Materials and Methods: Seventy-two mandibular incisors were randomly divided into six groups according to the system used: WaveOne (WO), Reciproc (RP), Unicone (UC), ProTaper Next (PN), Mtwo (MT), and HyFlex (HF). Afterward, the specimens were cleaved in the mesiodistal and buccolingual direction for analysis by scanning electron microscopy. Results: Considering both directions and root canal thirds, there was no difference between HF, MT, and PN. RP, UC, and WO presented a significant difference between the directions, and the cervical third showed a significantly smaller quantity of residual smear layer compared with the apical third. When the systems were compared among them, there was a significant difference only between RP and WO. Conclusions: Residual smear layer observed after instrumentation with the different systems was similar, except for quantities between the reciprocating systems.

Key words: Nickel-titanium, scanning electron microscopy, smear layer

\section{INTRODUCTION}

The thermomechanical treatment of nickel-titanium (NiTi) alloys, resulting in changes in the microstructure of instruments, has accentuated some of their properties such as flexibility and

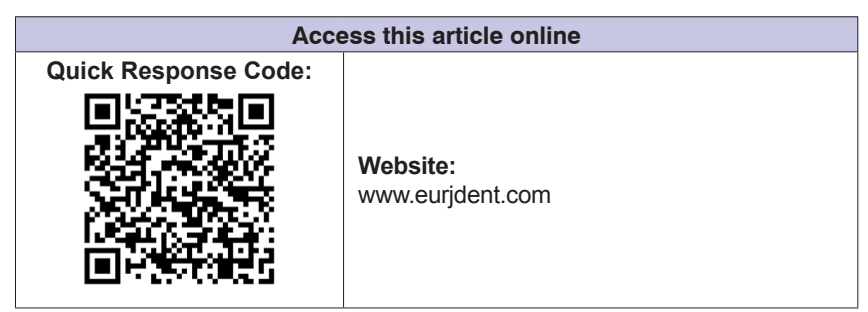

elasticity to an even greater extent. Within this class of instruments, those manufactured with

This is an open access journal, and articles are distributed under the terms of the Creative Commons Attribution-NonCommercial-ShareAlike 4.0 License, which allows others to remix, tweak, and build upon the work non-commercially, as long as appropriate credit is given and the new creations are licensed under the identical terms.

For reprints contact: reprints@medknow.com

How to cite this article: Machado R, Comparin D, Engelke Back ED, Roberti Garcia Ld, Alberton LR. Residual smear layer after root canal instrumentation by using Niti, M-Wire and CM-Wire instruments: A scanning electron microscopy analysis. Eur J Dent 2018;12:403-9.

DOI: 10.4103/ejd.ejd_259_17 
M-Wire, and more recently, CM-Wire technology are outstanding. ${ }^{[1,2]}$

The instruments made of M-wire, are manufactured by transformation of the martensitic phase of the alloy into the austenitic phase, when they are submitted to a certain stress. ${ }^{[3]}$ When this stress is removed, there is a spontaneous reversion of the alloy microstructure to the martensitic phase ${ }^{[3]}$ This process guarantees the greater flexibility of the instrument, and consequently, greater resistance to cyclic and torsional fatigue than that of the instruments made of conventional NiTi. ${ }^{[2,3]}$ From then on, systems appeared, which use movements that differ from those of the conventional rotary type, such as the reciprocating type, and these are capable of performing root canal preparation with a reduced number of instruments. ${ }^{[4,5]}$

Whereas, instruments made of CM-Wire alloy are among the latest innovations. In this case, thermal treatment has led to the transformation of the austenitic phase of the alloy into an intermediate phase between this phase and the martensitic phase, denominated the R-phase. This treatment promotes a controlled memory effect on the alloy, allowing instruments to curve significantly under a determined stress, and recovering their original form when the stress is removed. ${ }^{[2,6]}$

These characteristics give the different instrumentation systems different cutting capacities, and therefore, distinct potentials in relation to smear layer production. ${ }^{[1,2,7-10]}$ Nevertheless, in the same way that they are produced, instruments should be capable of mechanically removing a significant part of this smear layer because its removal is necessary before the use of intracanal medications or performing root canal filling, to ensure the success of endodontic treatment. ${ }^{[11]}$

Thus, the purpose of this study was use scanning electron microscopy analysis, to compare the amount of residual smear layer after root canal preparation with NiTi, M-Wire, and CM-wire instruments. The null hypothesis tested was that there would be no difference relative to the quantity of residual smear layer after the use of the different systems tested.

\section{MATERIALS AND METHODS}

\section{Selection and preparation of teeth}

To conduct this study, 72 mandibular incisors, without curvatures, resorptive processes, previous endodontic treatment, and anatomic complexities were selected The external root surfaces of the teeth were cleaned with ultrasound (Profi II Ceramic, Dabi Atlante Ltda., Ribeirão Preto, SP, Brazil). Then, the samples were stored in receptacles containing a $0.2 \%$ thymol solution, followed by washing in running water for disinfection for $24 \mathrm{~h}$.

Afterward, the crowns of the teeth were sectioned close to the amelocemental junction, by using a double-faced disc (KG Sorensen, Barueri, SP, Brazil), to standardize the root segments to a length of $13 \mathrm{~mm}$.

\section{Biomechanical preparation}

Root canal entrances were prepared with largo burs No. 2 (Dentsply/Maillefer, Ballaigues, Switzerland) and 3082 burs (KG Sorensen). The cervical and middle thirds were prepared with Gates Glidden drills No. 4, 3, and 2 (Dentsply/Maillefer), according to the crown-down technique. After this, the working lengths were determined by inserting a K-type \#10 instrument (Dentsply/Maillefer) until it could be visualized at the apical foramen and subtracting $1 \mathrm{~mm}$ from this measurement. For performing instrumentation of the root canals, the teeth were randomly divided into 6 groups $(n=12)$ according to the different systems used [Table 1].

All the root canals were instrumented by the same operator, using an X-Smart Plus motor (Denstply/Maillefer), in accordance with the recommendations of the manufacturers of each system as regards the torque applied. The canals were irrigated with $2.5 \%$ sodium hypochlorite solution (Fórmula and Ação, São Paulo, SP, Brazil)

\begin{tabular}{ccc}
\multicolumn{2}{c}{ Table 1: Disposition of experimental groups according to systems used for root canal preparations } \\
\hline Group & System/alloy (manufacturer) & Instruments used for preparation \\
\hline WO & WaveOne/M-Wire (Dentsply Tulsa Dental Specialties, Tulsa, OK, USA) & $21 / 0.06($ small) + 25/0.08 (primary) + 40/0.08 (large) \\
RP & Reciproc/M-Wire (VDW GmbH, Munich, Germany) & $25 / 0.08(\mathrm{R} 25)+40 / 0.06(\mathrm{R} 40)$ \\
UC & Unicone/NiTi - refined alloy (Medin, Lachovická, Czech Republic) & $20 / 0.06($ yellow) $+25 / 0.06($ red $)+40 / 0.06(\mathrm{black})$ \\
PN & ProTaper Next/M-Wire (Dentsply Tulsa Dental Specialties) & $17 / 0.04(\mathrm{X} 1)+25 / 0.06(\mathrm{X} 2)+30 / 0.07(\mathrm{X} 3)+40 / 0.06(\mathrm{X} 4)$ \\
MT & Mtwo/NiTi (VDW) & $10 / 0.04+15 / 0.05+20 / 0.06+25 / 0.06$ \\
& & $+30 / 0.05+35 / 0.04+40 / 0.04$ \\
HF & HyFlex CM/CM-Wire (Coltène/Whaledent AG, Altstätten, Switzerland) & $25 / 0.08+20 / 0.04+25 / 0.04+20 / 0.06+30 / 0.04+40 / 0.04$ \\
\hline
\end{tabular}


at every change of instrument, and on conclusion of instrumentation, totaling $20 \mathrm{~mL}$ of irrigant solution. Subsequently, $5 \mathrm{~mL}$ de $17 \%$ ethylenediaminetetraacetic acid (EDTA) (Maquira Dental Products, Maringá, PR, Brazil) was applied for 5 min inside the root canal to remove the smear layer, then abundant irrigation was performed with $0.9 \%$ saline solution. The root canals were irrigated using a 30G needle (Navitip, Ultradent Products Inc., South Jordan, UT, USA) calibrated to reach $2 \mathrm{~mm}$ short of the working length. In two teeth of each group, the EDTA was not used, with the aim of obtaining control specimens.

\section{Analysis by scanning electron microscopy}

In each group, 6 teeth were randomly selected to have longitudinal grooves made in the mesiodistal and buccolingual directions, using a flexible double-faced diamond disc (KG Sorensen). Final cleavage was performed with cutting pliers with the aim of exposing the root canal in both directions (mesiodistal and buccolingual). The hemisections were then fixed on circular metal stubs for sputter-coating the surface with a $30 \mathrm{~nm}$ thickness of gold (Quorum Q150R ES, Ashford Kent, UK). For each hemisection, images were captured at $\times 1000$ magnification, corresponding to each root third, using a scanning electron microscope (SEM) (Tescan VEGA 3, Tescan, Brno, Czech Republic).
Three previously calibrated, blinded examiners (Kappa test - 96\% agreement) classified the residual smear layer residual, according to the criteria of Torabinejad et al.:[12] (1) absence or small quantity of smear layer; (2) moderate presence of smear layer; and (3) dense smear layer covering practically all the dentinal tubule entrances.

\section{Statistical analysis}

The data were analyzed relative to normality using the Lilliefors test. Due to their nonparametric distribution, the Mann-Whitney and Kruskal-Wallis tests for the analysis of variance were used $(P<0.05)$. For multiple comparisons, the Student-Newman-Keuls test was used with a level of significance of $5 \%$. Data were analyzed using Minitab 17.0 software (Minitab Inc., State College Philadelphia, PA, USA).

\section{RESULTS}

Representative SEM images of the cleaning capacity of the different systems tested may be visualized in Figures 1-3. Irrespective of the system used for preparing the canals, a significantly larger quantity of smear layer was observed in the buccolingual in comparison with the mesiodistal direction $(P<0.05)$ [Table 2]. Similarly, when comparing the root canal thirds, the quantity of smear
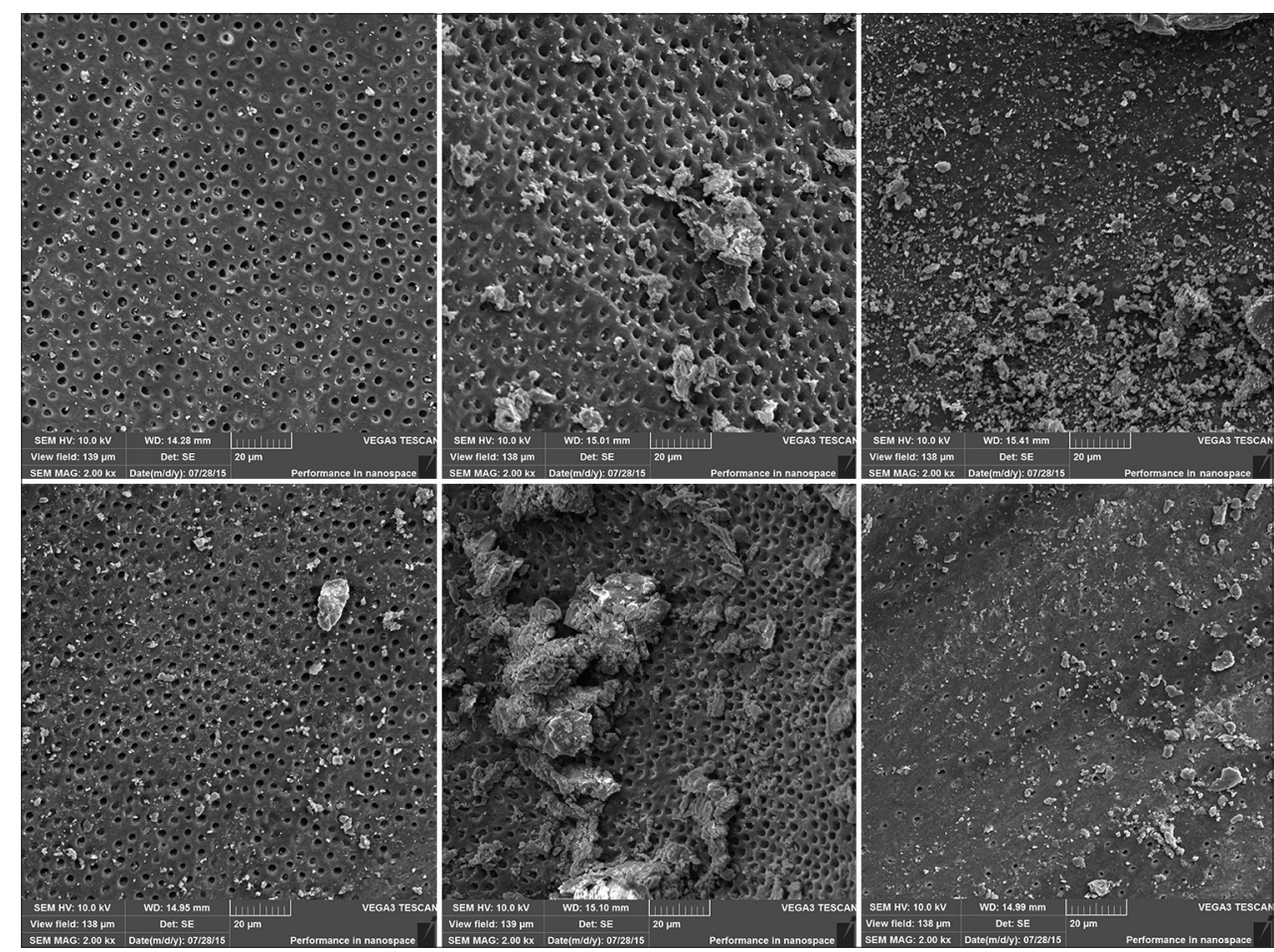

Figure 1: Scanning electron microscope images representative of the root canal walls in the mesiodistal (above) and buccolingual (below) directions after instrumentation with the HyFlex system. Please observe the similar quantity of smear layer adhered in both directions of analysis, and in the root canal thirds (cervical-left; middle-center; and apical-right) $(\times 1000)$ 

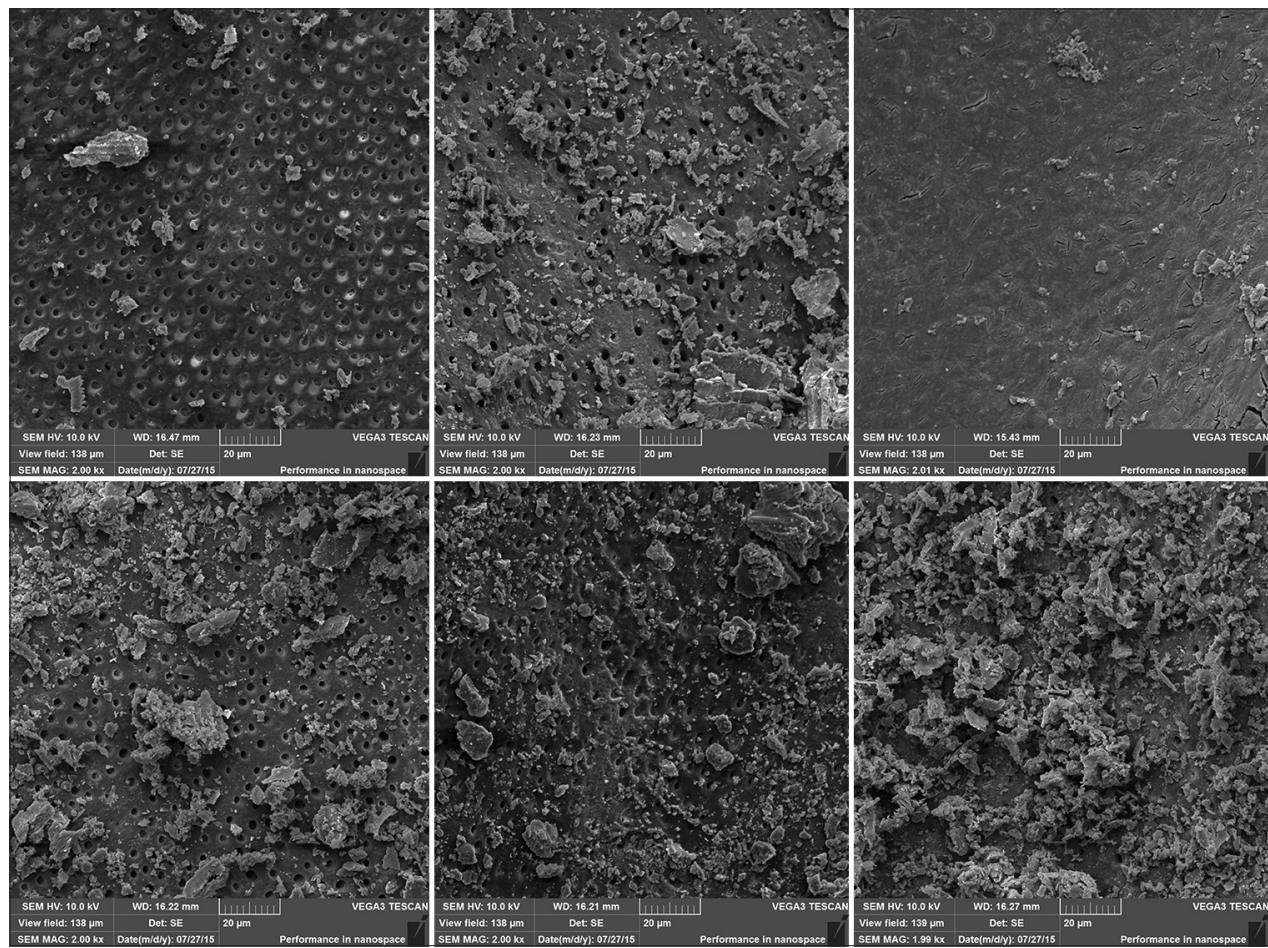

Figure 2: Scanning electron microscope images representative of the root canal walls in the mesiodistal (above) and buccolingual (below) directions after instrumentation with the Unicone system. Please note the significant difference in the quantity of smear layer adhered to the dentin substrate in the two directions of analysis. A significantly larger quantity of smear layer could be observed from the cervical (left) to the apical (right) region, in both directions of analysis $(\times 1000)$

layer increased significantly from the cervical to the apical region [Table 3].

When the systems were considered in the comparison between the two directions of analysis and root canal thirds [Table 4], there was no statistical difference between Groups HyFlex, Mtwo (MT) and ProTaper $\operatorname{Next}(P>0.05)$. The specimens in Groups Reciproc (RP), Unicone, and WaveOne (WO) presented a significant difference between the directions of analysis $(P<0.05)$, and the cervical third showed a significantly smaller quantity of residual smear layer compared with the apical third $(P<0.05)$.

When the same systems were compared among each other, considering both directions of analysis and the three root canal thirds, there was statistically significant difference only between Groups RP and WO $(P<0.05)$ [Table 5].

\section{DISCUSSION}

The aim of this study was to make a quantitative evaluation of the residual smear layer after root canal instrumentation with systems made of different NiTi alloys. Based on the results obtained, the null hypothesis tested was partially rejected, since the

Table 2: Values referring to smear layer removal in
the mesiodistal and buccolingual directions
\begin{tabular}{lcccc}
\hline Direction & $\boldsymbol{n}$ & Median & Quartile deviation & $\boldsymbol{P}$ \\
\hline MD & 90 & $1.00^{\mathrm{a}}$ & 0.50 & 0.0007 \\
$\mathrm{BL}$ & 90 & $2.00^{\mathrm{b}}$ & 2.20 & \\
\hline
\end{tabular}

Different lowercase letters indicate statistically significant difference $(P<0.05)$. MD: Mesiodistal, BL: Buccolingual

Table 3: Values referring to smear layer removal in
the different root canal thirds
\begin{tabular}{lcccc}
\hline Root canal third & $\boldsymbol{n}$ & Median & Quartile deviation & $\boldsymbol{P}$ \\
\hline Cervical & 60 & $1.00^{\mathrm{a}}$ & 1.50 & 0.000 \\
Middle & 60 & $2.00^{\mathrm{b}}$ & 2.50 & \\
Apical & 60 & $3.00^{\mathrm{c}}$ & 2.00 & \\
\hline
\end{tabular}

Different lowercase letters indicate statistically significant difference $(P<0.05)$

different systems presented a similar performance, with the exception of the comparison between the WO and $\mathrm{RP}$ systems. In spite of the superior performance of the WO system in comparison with RP, it is worth pointing out that the two systems are manufactured of the same alloy (M-Wire), demonstrating that this factor of itself does not play a fundamental role in the production and removal of smear layer by these instruments.

Although they are made of the same alloy, the reciprocal systems tested in this study had different 

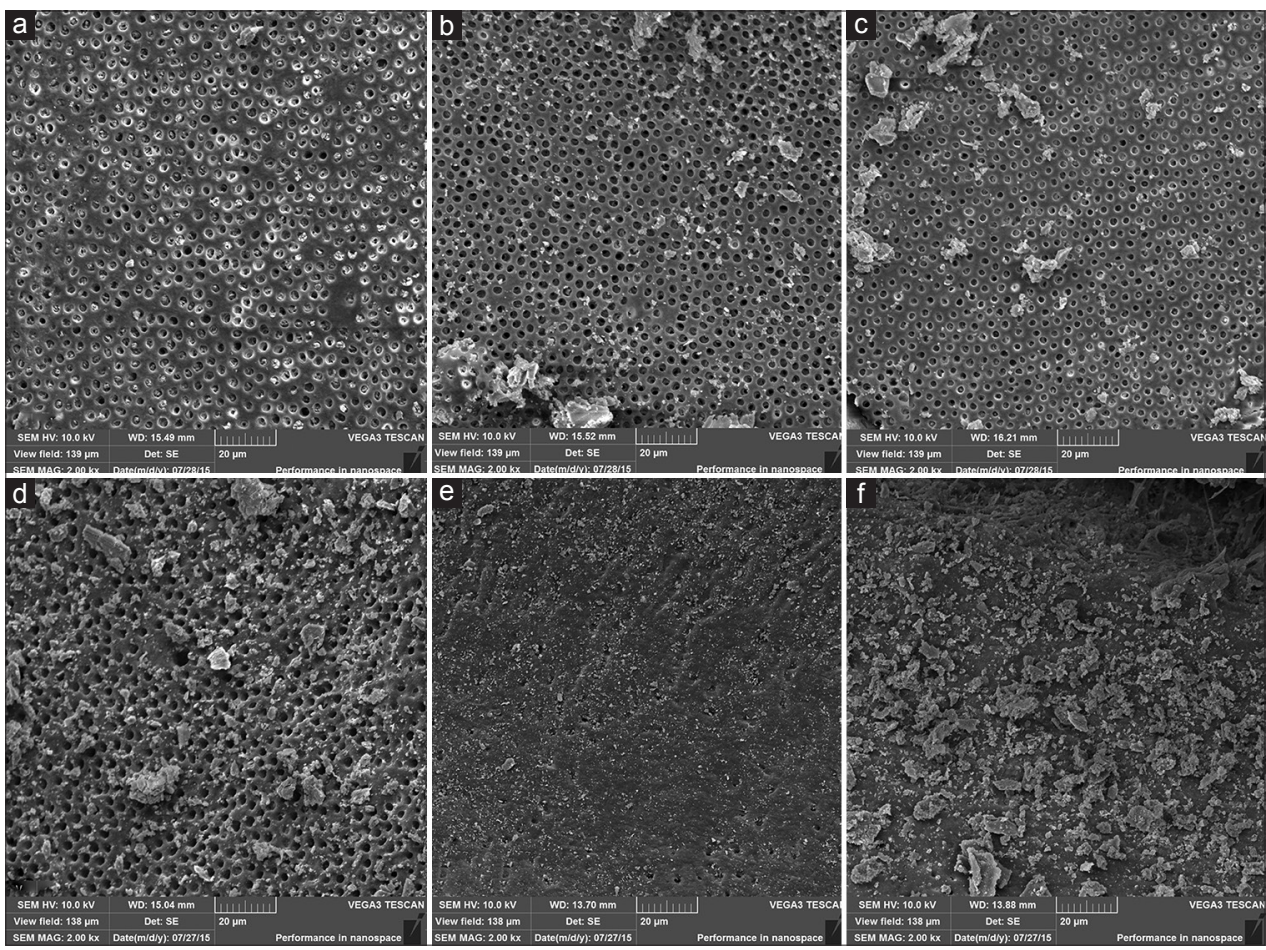

Figure 3: Scanning electron microscope images representative of the root canal walls (mesiodistal direction) after action of the tested systems. Cervical (a), middle (b), and apical (c) thirds of the group instrumented with the WaveOne System. Note signifi cant increase in the quantity of smear layer from the cervical to apical region; the same could be observed in the cervical (d), middle, (e) and apical (f) thirds of the samples of group Reciproc. Moreover, it was possible to observe a signifi cantly larger quantity of smear layer in Group Reciproc in comparison with Group WaveOne (×1000)

\begin{tabular}{lcccc}
$\begin{array}{l}\text { Table 4: Smear layer removal in each group, considering } \\
\text { the direction of analysis and the root canal thirds }\end{array}$ \\
$\begin{array}{lcccc}\text { Group/direction } \\
\text { of analysis }\end{array}$ & \multicolumn{3}{c}{ Root canal third } & $P$ \\
\cline { 2 - 4 } & Cervical & Middle & Apical & \\
\hline WO/MD & $1.0 \pm 0.5$ & $1.0 \pm 0.5$ & $2.0 \pm 1.5$ & $*$ \\
WO/BL & $1.0 \pm 0.5^{\mathrm{a}}$ & $1.0 \pm 1.5^{\mathrm{a}, \mathrm{b}}$ & $3.0 \pm 2.0^{\mathrm{b}}$ & 0.01 \\
$\mathrm{RP} / \mathrm{MD}$ & $1.0 \pm 0.5^{\mathrm{a}}$ & $3.0 \pm 2.0^{\mathrm{b}}$ & $2.0 \pm 2.0^{\mathrm{b}}$ & 0.028 \\
$\mathrm{RP} / \mathrm{BL}$ & $2.0 \pm 1.5^{\mathrm{a}}$ & $3.0 \pm 1.5^{\mathrm{a}, \mathrm{b}}$ & $3.0 \pm 1.5 \mathrm{c}$ & 0.028 \\
UC/MD & $1.0 \pm 1.5$ & $1.0 \pm 0.5$ & $3.0 \pm 2.5$ & $*$ \\
UC/BL & $2.0 \pm 1.5^{\mathrm{a}}$ & $3.0 \pm 2.0^{\mathrm{b}}$ & $3.0 \pm 2.0^{\mathrm{b}}$ & 0.04 \\
$\mathrm{PN} / \mathrm{MD}$ & $1.0 \pm 1.5$ & $1.0 \pm 1.5$ & $2.0 \pm 2.5$ & $*$ \\
$\mathrm{PN} / \mathrm{BL}$ & $1.0 \pm 1.5$ & $2.0 \pm 1.5$ & $2.0 \pm 2.5$ & $*$ \\
MT/MD & $1.0 \pm 1.5$ & $1.0 \pm 1.5$ & $2.0 \pm 1.5$ & $*$ \\
MT/BL & $2.0 \pm 1.0$ & $2.0 \pm 2.0$ & $3.0 \pm 1.5$ & $*$ \\
HF/MD & $1.0 \pm 1.5$ & $2.0 \pm 1.5$ & $3.0 \pm 2.5$ & $*$ \\
HF/BL & $1.0 \pm 0.5^{\mathrm{b}}$ & $2.0 \pm 1.0^{\mathrm{a}, \mathrm{b}}$ & $3.0 \pm 1.5^{\mathrm{a}}$ & 0.0063 \\
\hline DHfert & &
\end{tabular}

Different lowercase letters indicate statistically significant difference $(P<0.05)$. *Without statistically significant difference $(P>0.05)$. WO: WaveOne, RP Reciproc, UC: Unicone, PN: ProTaper Next, MT: Mtwo, HF: HyFlex, MD: Mesiodistal, BL: Buccolingual

cross-sections. RP instruments have an S-shaped cross-section blade and WO instruments a triangular concave design. ${ }^{[13]}$ According to Burklein et al..$^{[14]}$ the cross-sectional design of the RP system instruments favors the removal of the smear layer and debris, because it has deeper indentations than those of the WO instruments, thereby optimizing its cleaning capacity. However, other studies have demonstrated that there were no differences between the systems relative to the cleaning promoted in the root canal. ${ }^{[15,16]}$ These results differ from those obtained in the present research because the WO system showed smear layer removal capacity superior to that of RP.

The RP system instruments have greater dentin cutting capacity than that of the WO system instruments. ${ }^{[17]}$ The greater the cutting capacity of an instrument, the greater will be its smear layer production. ${ }^{[18-21]}$ This may explain the results obtained by the RP Group in the present study. Moreover, the WO system instruments have a larger cross-sectional area than that of the RP system instruments. ${ }^{[13]}$ This feature of the cross-section allows greater contact between the instrument and root canal wall, promoting greater drag on the smear layer adhered to it. ${ }^{[22]}$

Furthermore, it is valid to point out that the manufacturers of the different reciprocating systems normally recommend the use of a single instrument for root canal preparation. ${ }^{[14]}$ However, in the present study, more than one instrument was used due to two factors; to obtain an automated glide path for the use of instruments with a larger tip and taper, ${ }^{[8,23]}$ and to 


\begin{tabular}{|c|c|c|c|c|}
\hline Groups & $n$ & Median & Quartile deviation & $P$ \\
\hline WO & 30 & $1.00^{\mathrm{b}}$ & 1.50 & 0.0029 \\
\hline $\mathrm{RP}$ & 30 & $2.50^{\mathrm{a}}$ & 2.50 & \\
\hline UC & 30 & $2.00^{a, b}$ & 2.50 & \\
\hline PN & 30 & $1.50^{\mathrm{a}, \mathrm{b}}$ & 2.25 & \\
\hline MT & 30 & $2.00^{a, b}$ & 2.50 & \\
\hline $\mathrm{HF}$ & 30 & $2.00^{a, b}$ & 2.25 & \\
\hline
\end{tabular}

Different lowercase letters indicate statistically significant difference $(P<0.05)$. WO: WaveOne, RP: Reciproc, UC: Unicone, PN: ProTaper Next, MT: Mtwo HF: HyFlex

maintain the identical frequencies and quantities of irrigant solution for all the systems tested. ${ }^{[24,25]}$ Studies have demonstrated that for systems that use a reduced number of instruments, such as the reciprocating types, a glide path must previously be created to allow free access of the instrument to the entire working length of the root canal. ${ }^{[15,26]}$ Furthermore, due to the reduced number of instruments used during preparation, the quantity of irrigant solution used would also be reduced, compromising the cleaning capacity of these systems. ${ }^{[14]}$

The instruments of the MT system are made of conventional NiTi alloy, and although they have a lower degree of flexibility than those made of M-Wire, the results presented were similar. These instruments presented characteristics very similar to those of the RP system instruments, with an S-shaped cross-section, positive cutting angle, and two cutting edges. ${ }^{[10,27]}$ However, they also have an increasing pitch length that prevents the screwing effect of instruments and debris accumulation, thus achieving performance close to that of the WO system. ${ }^{[10,27]}$ Furthermore, the reciprocating movement itself is considered more aggressive than that of the continuous rotary movement, predisposing to a larger quantity of dentin excised and greater accumulation of smear layer and debris in untouched areas, such as the buccolingual walls. ${ }^{[28]}$

Considering the direction of analysis, the results of this study demonstrated that the buccolingual walls presented a larger deposition of smear layer when compared with the mesiodistal walls. The previous studies have demonstrated that particularly in teeth with flattened canals, such as the mandibular incisors, the vestibular and lingual walls may act as veritable niches for accommodating the smear layer and debris, ${ }^{[29,30]}$ a fact corroborated by our findings.
The same could be said as regards the root canal thirds since the preparation of the apical third is more critical, making it difficult to clean this area. ${ }^{[29,30]}$

\section{CONCLUSIONS}

In spite of the limitations of this ex vivo study, the systems tested presented similar performance as regards their capacity to remove the smear layer, irrespective of the alloy of which they were made. However, considering only the systems with reciprocating movement, WO had a performance superior to that of RP, which proved that factor such as the cross-section and shape of the instrument active tip were more relevant for smear layer production and removal than the type of alloy of which they are manufactured.

\section{Financial support and sponsorship \\ Nil.}

\section{Conflicts of interest}

There are no conflicts of interest.

\section{REFERENCES}

1. Gambarini G, Plotino G, Grande NM, Al-Sudani D, De Luca M, Testarelli L, et al. Mechanical properties of nickel-titanium rotary instruments produced with a new manufacturing technique. Int Endod J 2011;44:337-41.

2. Shen Y, Qian W, Abtin H, Gao Y, Haapasalo M. Fatigue testing of controlled memory wire nickel-titanium rotary instruments. J Endod 2011;37:997-1001.

3. Gutmann JL, Gao Y. Alteration in the inherent metallic and surface properties of nickel-titanium root canal instruments to enhance performance, durability and safety: A focused review. Int Endod J 2012;45:113-28

4. Silva EJ, Villarino LS, Vieira VT, Accorsi-Mendonça T, Antunes HD, De-Deus G, et al. Bending resistance and cyclic fatigue life of reciproc, unicone, and WaveOne reciprocating instruments. J Endod 2016;42:1789-93.

5. Grande NM, Ahmed HM, Cohen S, Bukiet F, Plotino G. Current assessment of reciprocation in endodontic preparation: A Comprehensive review-part I: Historic perspectives and current applications. J Endod 2015;41:1778-83.

6. Zhou HM, Shen Y, Zheng W, Li L, Zheng YF, Haapasalo M, et al. Mechanical properties of controlled memory and superelastic nickel-titanium wires used in the manufacture of rotary endodontic instruments. J Endod 2012;38:1535-40.

7. Bürklein S, Schäfer E. Apically extruded debris with reciprocating single-file and full-sequence rotary instrumentation systems. J Endod 2012;38:850-2.

8. Elnaghy AM, Elsaka SE. Evaluation of root canal transportation, centering ratio, and remaining dentin thickness associated with ProTaper next instruments with and without glide path. J Endod 2014;40:2053-6.

9. Wu H, Peng C, Bai Y, Hu X, Wang L, Li C, et al. Shaping ability of ProTaper universal, WaveOne and ProTaper next in simulated L-shaped and S-shaped root canals. BMC Oral Health 2015;15:27.

10. Schäfer E, Erler M, Dammaschke T. Comparative study on the shaping ability and cleaning efficiency of rotary Mtwo instruments. Part 1. Shaping ability in simulated curved canals. Int Endod J 2006;39:196-202.

11. Hargreaves KM, Cohen S, Berman LH. Cohen's Pathways of the 
Pulp. $10^{\text {th }}$ ed. St. Louis, Mo.: Mosby Elsevier; 2011.

12. Torabinejad M, Khademi AA, Babagoli J, Cho Y, Johnson WB, Bozhilov $\mathrm{K}$, et al. A new solution for the removal of the smear layer. J Endod 2003;29:170-5.

13. Kim HC, Kwak SW, Cheung GS, Ko DH, Chung SM, Lee W, et al. Cyclic fatigue and torsional resistance of two new nickel-titanium instruments used in reciprocation motion: Reciproc versus WaveOne. J Endod 2012;38:541-4.

14. Bürklein S, Hinschitza K, Dammaschke T, Schäfer E. Shaping ability and cleaning effectiveness of two single-file systems in severely curved root canals of extracted teeth: Reciproc and WaveOne versus Mtwo and ProTaper. Int Endod J 2012;45:449-61.

15. de Carvalho GM, Sponchiado Junior EC, Garrido AD, Lia RC, Garcia Lda F, Marques AA, et al. Apical transportation, centering ability, and cleaning effectiveness of reciprocating single-file system associated with different glide path techniques. J Endod 2015;41:2045-9.

16. Plotino G, Ahmed HM, Grande NM, Cohen S, Bukiet F. Current assessment of reciprocation in endodontic preparation: A Comprehensive review - Part II: Properties and effectiveness. J Endod 2015;41:1939-50.

17. Plotino G, Giansiracusa Rubini A, Grande NM, Testarelli L, Gambarini G. Cutting efficiency of reciproc and WaveOne reciprocating instruments. J Endod 2014;40:1228-30.

18. Abarajithan $\mathrm{M}$, Dham $\mathrm{S}$, Velmurugan $\mathrm{N}$, Valerian-Albuquerque $\mathrm{D}$, Ballal S, Senthilkumar $\mathrm{H}$, et al. Comparison of endovac irrigation system with conventional irrigation for removal of intracanal smear layer: An in vitro study. Oral Surg Oral Med Oral Pathol Oral Radiol Endod 2011;112:407-11.

19. Singh N, Chandra A, Tikku AP, Verma P. A comparative evaluation of different irrigation activation systems on smear layer removal from root canal: An in vitro scanning electron microscope study. J Conserv Dent 2014;17:159-63.
20. Violich DR, Chandler NP. The smear layer in endodontics - A review. Int Endod J 2010;43:2-15

21. Wu L, Mu Y, Deng X, Zhang S, Zhou D. Comparison of the effect of four decalcifying agents combined with $60^{\circ} \mathrm{C} 3 \%$ sodium hypochlorite on smear layer removal. J Endod 2012;38:381-4.

22. Amaral P, Forner L, Llena C. Smear layer removal in canals shaped with reciprocating rotary systems. J Clin Exp Dent 2013;5:e227-30.

23. Kirchhoff AL, Chu R, Mello I, Garzon AD, dos Santos M, Cunha RS, et al. Glide path management with single- and multiple-instrument Rotary Systems in Curved Canals: A micro-computed tomographic study. J Endod 2015;41:1880-3.

24. Howard RK, Kirkpatrick TC, Rutledge RE, Yaccino JM. Comparison of debris removal with three different irrigation techniques. J Endod 2011;37:1301-5.

25. Paqué F, Rechenberg DK, Zehnder M. Reduction of hard-tissue debris accumulation during rotary root canal instrumentation by etidronic acid in a sodium hypochlorite irrigant. J Endod 2012;38:692-5.

26. Berutti E, Paolino DS, Chiandussi G, Alovisi M, Cantatore G, Castellucci A, et al. Root canal anatomy preservation of WaveOne reciprocating files with or without glide path. J Endod 2012;38:101-4

27. Schäfer E, Erler M, Dammaschke T. Comparative study on the shaping ability and cleaning efficiency of rotary Mtwo instruments. Part 2. Cleaning effectiveness and shaping ability in severely curved root canals of extracted teeth. Int Endod J 2006;39:203-12.

28. Robinson JP, Lumley PJ, Cooper PR, Grover LM, Walmsley AD. Reciprocating root canal technique induces greater debris accumulation than a continuous rotary technique as assessed by 3-dimensional micro-computed tomography. J Endod 2013;39:1067-70.

29. Peters OA. Current challenges and concepts in the preparation of root canal systems: A review. J Endod 2004;30:559-67.

30. Paqué F, Musch U, Hülsmann M. Comparison of root canal preparation using $\mathrm{RaCe}$ and proTaper rotary $\mathrm{Ni}$-Ti instruments. Int Endod J 2005;38:8-16. 